\title{
Product Lifecycle Management in Education: Key to Innovation in Engineering and Technology
}

\author{
Priyanka Gandhi \\ ${ }^{1}$ Sr. PLM Consultant, USA \\ ${ }^{2}$ Independent Researcher \\ priyankagandhi9@gmail.com
}

\begin{abstract}
Product Lifecycle Management in Education is the key to innovation and success in organizations in the engineering and technology sector. This paper illustrates that incorporation of PLM training in coursework and education of best practices, processes and solutions at educational institutions as well as organizations helps leverage the intellectual assets of an organization and turn them into deliverable assets. PLM education and training imparts vision, technical expertise and solutions to improve productivity and efficiency in the fields of engineering, business, operations and supply chain in different industries such as OEMs their suppliers, retail, pharmacy and apparel industry etc. PLM training and applications of core methods, tools and processes achieve major cost savings and resource sharing between different business segments besides advancing the innovation in engineering and technology.
\end{abstract}

Keywords: PLM, Education, Efficiency, Supply Chain, OEMs, Tools and Processes, Training, Productivity, Innovation, Design Engineering.

\section{Introduction}

Product Lifecycle Management has become one of the fastest growing technology solutions in the last twenty years in engineering organizations. PLM has gained its popularity and established its scope in engineering, manufacturing, retail, apparel, pharmacy and various other industries. It has become imperative to educate employees of OEMs (Original Equipment Manufacturers) and the suppliers in the use of Product Lifecycle Management tools and processes. Usually the product development team and its members prior to the implementation of PLM methodologies lack the vision and empowerment to avoid wasteful PLM implementation procedures and err along the lifecycle of product development, thereby under-utilizing the "PLM potential" for a \%100 successful outcome[1].

Product Lifecycle Management education and training to experienced engineers and even recent graduates can help in producing better product development expertise, improvised skill and tool knowledge to carry out efficient design, technical competence to manage a large product base, industrial applicability to improve customer satisfaction and overall better engineering solutions to maintain and run existing processes seamlessly in the real world. Usually suppliers of engineering product/parts and services spend a humongous amount of resources in outsourcing the training and certification endeavors to OEMs or other suppliers 
to educate and certify their engineering workforce to $\mathrm{g}$ a i $\mathrm{n}$ the technological knowledge to excel in application of PLM solutions to their product lifecycles [2].

Many companies have therefore realized the added value brought about by PLM Education in cost saving strategies to leverage the quality and productivity of their Product development Lifecycle. One of the essential components of Product Lifecycle Management is the knowledge of PLM tools and their functionality that forms the "Software area of the PLM" [ 1]. The application of PLM knowledge to specific industries like Industrial, Aerospace, Automotive, Retail or Pharmaceutical requires the knowledge of software tools along with the ability to translate PLM vision and strategy to good design practices and philosophies. Thus application based PLM training involving case studies from experts of the specific industry, industry specific lessons learnt, knowledge of the known wasteful processes, all form an application based approach in PLM training and coaching [7].

Organizations u s i n g PLM technology are actively seeking PLM Education and training for their workforce thus driving PLM Education to schools and institutions to lay stress on their need for improving productivity and eliminating engineering design downtime. Utilizing PLM- efficient systems to drive productivity and resource sharing between isolated business segments that don't interact with each other and are relatively closed niche has become one of the most important goals along with core functional areas such as engineering design and product development. Karina Kogan, President of Business Management Systems at Vertex believes that PLM education is core to the success of PLM implementation in any industry. She further goes on to saying that, Vertex encourages fresh graduates and students right out of college to work in the fields of PLM and that they are even willing to go a step further beyond and install their tools and products at educational institutions so that they can be trained in fields of PLM before starting out work [5].

Sue Welch, the CEO at Tradestone Software, states that she is very interested in capturing fresh talent as well as educating them on the real-world applications of PLM in the direction to succeed as future PLM leaders of the retail industry. Laura McCann, who is the CEO at Zweave, has been able to launch the first academic PLM project that supports PLM education in the retail and fashion industry. This enables the students to get the PLM knowledge and industrial experience at a much affordable cost. Gerber technology has provided free software to educational institutions for about 40 years now, so as to produce talented PLM consultants that are well versed in the PLM technology [1]. The V.P. of Vertical Market Strategy at PTC, Kathleen Mitford says that, PTC has always pioneered PLM education at the university levels and has provided the PTC software solutions to the academic institutions for learning and development purposes. Lenny Weiss, the V.P. of sales and marketing at Yunique Solutions, says that Yunique has provided access to their PLM tools and processes to the students at FIT (Fashion Institute of Technology) to provide PLM training to the student fraternity in the retail and fashion industry. Phillippe Ribera, the PLM development manager at Lectra, states that they target over 680 fashion and design institutions to impart PLM education. Over 70 schools have implemented coursework and training on PLM technology solutions and design technology developed by Lectra in their curriculum in order to produce well trained PLM graduates for the retail and fashion industry [1].The Vice President of R\&D at Visual 2000 International, Charles Benoualid, states that he has always championed the give and take philosophy on PLM in Education. The give and take model allows him to supply free PLM software and technology for training purposes to students at universities to teach them about real life PLM technology solutions and in return the highly learned scholars in design and production with advanced degrees end up providing real solutions to customers across the globe. There are a few companies which are still thinking and giving consideration to the PLM in education perspective but are yet to adopt it. Lawson and Porine spA are a few to name [1]. 


\section{$2 \quad$ PLM Training at Educational Institutions and Universities}

\subsection{PLM Education at Purdue University}

Purdue University has developed a detailed Research and Development Program to foster the Product Lifecycle Management subject as a philosophy and as a tool that will serve as an important building block in producing successful industry leaders in this area of technology [7]. The PLM center of excellence at Purdue is a collaboration of the colleges of engineering, science and management, that have come together to conceive a "one stop" PLM educational research and training center to the academia and industries [1]. Purdue aims at propagating through this institute the best industry standards in PLM tools and technology by partnering with the PLM giants in business and merging them with the PLM educational community. The goals of this Research and Development center at Purdue is to advance the Product Lifecycle Management Tools and approaches by leveraging the existing PLM solutions from the techindustry [11].

Purdue University understands the value and significance of PLM as a technology and as a management discipline in today's day and age of technological innovation. The benefits of Product Lifecycle Management as comprehended at Purdue are multiple; from better visualization and management of product data management to increasing the productivity and quality of the end product, it truly understands the potential of PLM and its unrealized scope [1].Purdue professes that PLM brings about streamlined product development at reduced costs through the different lifecycle stages of the product evolution from inception, execution to maturity in engineering design, manufacturing as well as maintenance disciplines. Encouraging PLM in Education Industry is the fundamental goal of the PLM R\&D center at Purdue. Purdue University aims to establish $s$ t rategic $r$ elatio $n$ sh ip $s$ w it h key organizations with a PLM focus through this media [1]. Purdue hopes to surface the advancements in PLM technology from time to time and propagate the PLM tools and training in the academia t o produce future leaders. It also aims at producing better PLM career prospects and seek funding for developing the PLM R\&D Initiative. Purdue also has a vision of bringing brand new organizations on board with PLM tools and technology and encouraging more and more educational institutions to incorporate PLM coursework in their curriculum [1].

\subsection{PLM Education at Michigan Technological University}

The PHD program in Mechanical Engineering at Michigan Technological University (MTU) has Product Lifecycle Management as one of its main focus areas under the mechanical engineering umbrella. The PHD program at MTU is one of its kind research intensive programs that foster PLM as one of the research areas of course work and dissertation. The Graduate ranking of the Doctoral Program is 48th across US according to America's best college rankings. The Undergraduate degree program in Mechanical Engineering is ranked $22^{\text {nd }}$ across US according to the Americas best college rankings. MTU is a pioneer institution that has about 7000 students enrolled in graduate and undergraduate degree programs. There are about 130 programs in arts, sciences, engineering, and several other subjects at MTU [1].

In order to obtain the undergraduate d egree at MTU, the students need to do a senior design capstone project that tests their design knowledge. In a group of 4 to 6 students they participate in this design challenge which is believed to be more of a first job for them rather than their last class. Michigan Technological University is one of the Major Customers of Siemens that is the creator of Unigraphics their signature PLM tool and solution. Students learn Unigraphics (NX) in their undergraduate degree program when they start out and use their design skills along with the PLM software tool knowledge to propose innovative design solutions and their CAD Design skills [1]. 
A typical example of a senior capstone design project was a case study with whirlpool dryers that ended up resulting in a 11 cents/ unit saving adding up to $\$ 1.85$ million savings for the company annually [Fig 1]. There was an option to use Pro-E as the CAD tool but the Unigraphics tool's CAM option was more suitable and familiar for the senior design team. The systems noise level requirement was also taken into consideration and there were two options developed but it was demonstrated that one of the option that couldn't meet the systems noise requirements was rejected and the other option which met or exceeded the systems noise level requirements was chosen which led to savings of 11 cents per unit and $\$ 1.85$ million annually [10].

PACE is the "Partners for the Advancement of Collaborative Engineering Education" Program that links several institutions academically including the Michigan Technological University for the development of PLM solutions that cater to the automotive OEMs. Several key team players of the Automotive Industry participate in judging the PACE endeavor like GM, Siemens, HP, Oracle, etc. PACE fosters the goals of PLM to provide Product Lifecycle Management as an integrated engineering solution from conceptualizing, product development, marketing, distribution, maintenance and ultimately disposition and recycling of the product, if necessary [7].

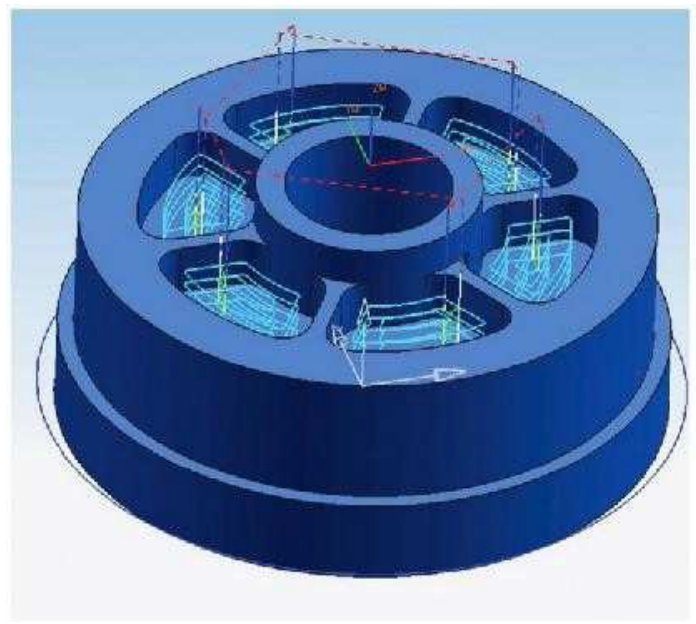

Fig. 1. Whirlpool Dryer Senior Design Capstone Project at Michigan Technological University. A dryer designed by MTU students that led whirlpool to alter its design and bring about savings worth $\$ 1.85$ million dollars is shown above.

Michigan Technological University teaches a program on engineering modeling and design course the ENG1102 where eight students participate annually in the PACE design competition showcasing innovative design solutions to a panel of judges appointed by the MTU. The criteria for the selection of the best design project includes, form, fit, function of the design and the presentation and feasibility of the design. Examples of PACE winning team projects include a robotic vehicle and projects utilizing the alternative energy sources like solar and wind energy [9].

\subsection{PLM Education at Oakland University}

The center for Product Lifecycle Management at Oakland University in Michigan is one of its kind institutes that inculcate the important lessons of PLM implementation in the form of coursework offerings. Oakland University has developed a center for PLM Education 
that will touch upon the three areas of Product Development, PLM (Product Lifecycle Management), ERP (Enterprise Resource Planning) and MES (Manufacturing E x e c u t i o n Systems) in order to keep the jobs within the state of Michigan itself [Fig 2] [8].

The goals of the Academic Center of Excellence for PLM at Oakland University can be summarized into the following five points [Fig 3]:

1. To act as the main point of origination of Leadership Strategies for Development of the PLM Workforce.

2. Collaborate the academic center for PLM with Local K-12 schools and community colleges.

3. To help in the development of virtual manufacturing labs.

4. To help in the IT maintenance of the PLM centers for various academic institutions and schools.

5. Provide Educational Development of PLM, ERP and MES areas by including coursework in PLM in the existing Masters in Engineering and Management programs.

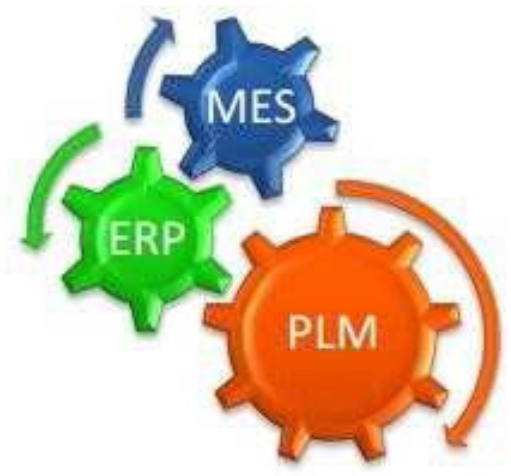

Fig. 2. Functional Areas of I.T. Enterprise Architecture. The figure shows the three integrated areas of Product Lifecycle Management, Enterprise Resource planning, and Manufacturing Execution Systems [6].

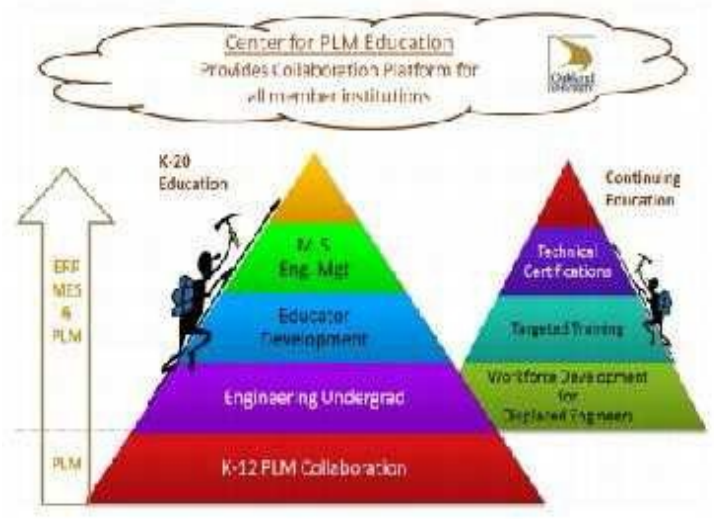

Fig. 3. Academic Center for PLM at Oakland University. This figure shows the breakdown of integrated areas of PLM. 
The academic center of PLM development at Oakland University realized that Product Lifecycle Management (PLM) consists of the following steps, also summarized in Fig 4 [11].

1. Recognition of the market/ niche of the product.

2. Design of the products based on the business requirements.

3. Analysis of the performance criteria of the product

4. Manufacturing of the Product.

5. Customer Satisfaction and Product Support through its Lifecycle.

6. Reducing the impact of the product on the environment thus easing the recycling and disposition process.

The academic institutions in Michigan are striving hard to develop the PLM skills in their students and while doing so they face the challenge of lack of I.T. infrastructure to provide them with the necessary tools and processes. A collaborative online approach that provides them the necessary tool infrastructure and support along with the course curriculum is thus needed [1].

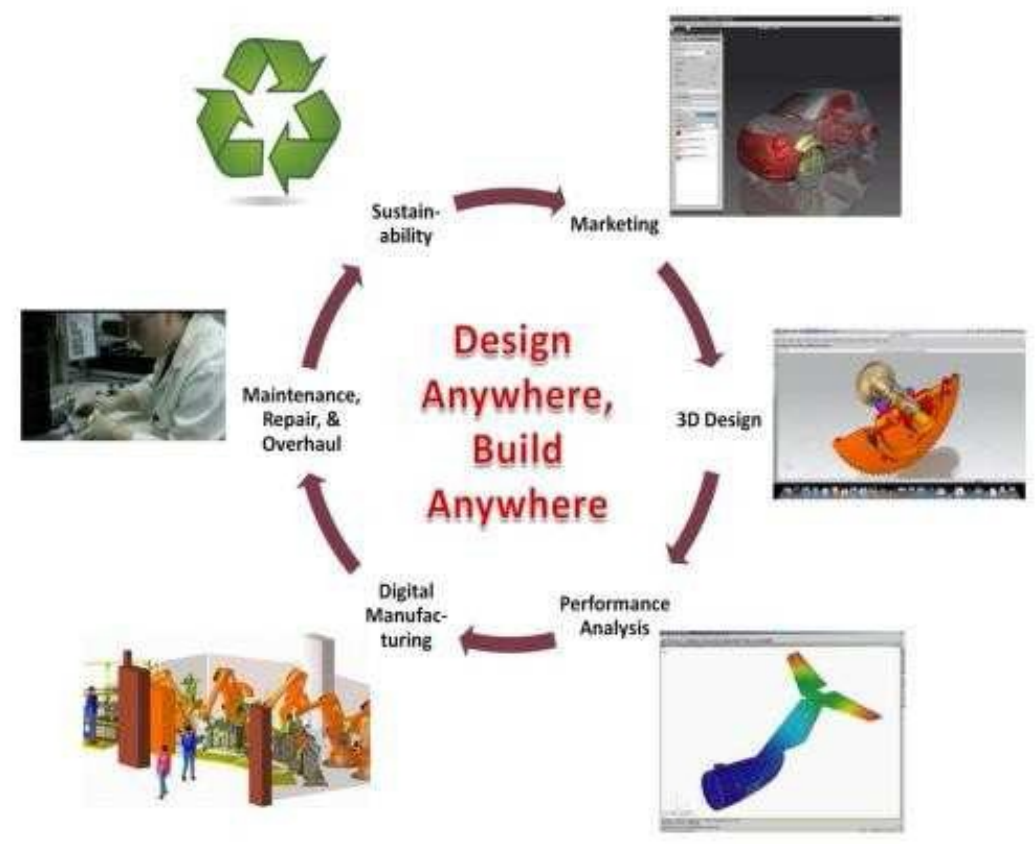

Fig. 4. Stages of PLM. This figure shows the different stages of Product lifecycle management.

The academic center has relationships with essential PLM vendors that can help provide the necessary IT infrastructure and the non-member academic institutions can in turn partner with this academic center in order to reap the benefits of their accessibility to the PLM tools and technology made available at this academic center. The academic center is also aiming at providing software tools installation and IT support to the member schools and services as the IT hub that all the member institutions can go to with license installation issues and tool support requirements [1].The academic center also aims at including PLM course offerings 
especially in the technology track courses like the masters in engineering management program to include the PL/ERP/MES courses. The academic center also aims at starting virtual manufacturing labs where the member institutions can access the software tools necessary to simulate manufacturing environments to test the feasibility of their product design. Virtual labs are better than physical labs since they do not need the full scale IT infrastructure to function [7]. As schools always face the lack of funds and staff to maintain and run the individual labs, the virtual labs help them to train their students in manufacturing domain of the PLM without the need to set up an actual lab [3]. The goals of the academic center are clearly also in line with the vision of President Obama who envisions that America is in need of smarter engineering and manufacturing solutions that create products and jobs within America versus outsourcing them to Asia or Europe. For the overall success of technology and innovation in USA, it's imperative to bring technology learning in schools and at the academic level [2].

\section{$3 \quad$ Strategic Partnerships between Academic Institutions and Organizations to foster PLM}

One example of a significant relationship between academic institutions and Organizations in the fields of PLM is the example of Siemens and Oakland University located in Rochester, Michigan. Siemens has provided Oakland University approximately \$12 million in software licenses and products that will directly benefit the students in becoming future PLM leaders. Siemens has always propagated that it will support Oakland University in producing smart graduates that are well versed in PLM design and implementation methodology. In order to encourage and support Oakland University's PLM center's initiative, Siemens has come forth and provided the access to software licenses particularly the Technomatix Robcad Software amounting to $\$ 11,846,850$. This software will enable in design, validation as well as automation of the manufacturing processes [1].

This is a pure example of academic institutions partnering with organizations to foster PLM education in Research and Development. Professor Robert Van Til from the department of Industrial and Systems Engineering Department vouches for the contribution of Siemens PLM software in establishing Oakland University as a premier PLM R\& D center. Oakland University believes that this software along with other software licenses and products supplied by Siemens helps greatly in producing educated PLM graduates and helps promote the quality of the academic program significantly. Tom Hoffman, marketing director at Siemens PLM software for manufacturing processes believes that Siemens has been and will continue to be a major contributor to the academic wealth and knowledge bank in the field of PLM at academic institutions like Oakland. Organizations like Siemens have contributed significantly in turning South East Michigan as a major hub of PLM Engineering Services. Siemens feels privileged to be a supporter of the "STEM" programs offered at Oakland University. In return the students from Oakland University contribute to the lean manufacturing processes through these robotic software licenses [11]. Siemens has a distinct interest in donating and giving back to the community through its "GO PLM" initiative. The director of "GO PLM" initiative, Hula King says that they want to continue to provide PLM licenses and software to Oakland University to encourage the R\&D Center to grow, as these software tools are not available readily and only used by multinational companies across the globe. This is a huge advantage to the academic development. Professor Robert Van also states that Siemens support further extends to training and support in the usage of their software and products to their academic community [7].

Dassault Systems is the world leader in PLM tools and technology like ENOVIA, DELMIA and SIMULIA. Dassault Systems and Oakland University have also partnered in coming up with a short 4 weeks post graduate course in PLM at the Academic Center for PLM research and development. This course has been developed with the collaboration of the School of Engineering and Computer Sciences (SECS) that integrates both engineering and business 
expertise. The main goal of this partnership was to retain the workforce within Michigan and to further the PLM endeavor as well [7]. Displacement of worked due to involuntary job loss was a common phenomenon in 2009 due to recession and to avoid the displacement of engineering workforce this step was taken[5].

Roy Smolky of DELMIA Academic Relations Program from Dassault believes that this program is the right step in the direction of retaining workforce within Michigan State itself as well as spreading the importance of the PLM subject matter expertise to produce future PLM leaders. The students during the course will be learning in detail the Dassault System DELMIA suite of tools for digital manufacturing and production and after completion of the course they will be administered to take the DELMIA proficiency certification exam. Professor Robert Van feels that this course is different from conventional professional courses as it is more hands on in training provided by Dassault Systems in the tools which will definitely experience double digit growth in the next 5 years [4].

Acknowledgments. Purdue Center of R\&D for PLM, Oakland Center for PLM, MTU Center for PLM, Whirlpool, Dassault Systems.

\section{References}

1. Stark, J.: Product Lifecycle Management, 21st Century Paradigm for Product Realization, 2nd edn. Springer

2. Xu, X.W., Liu, T.: A Web-Enabled PDM System in a Collaborative Design Environment. Robotics and Computer-Integrated Manufacturing 19, 315-328 (2003)

3. Understanding Product Lifecycle Management, Datamation Limited (2002)

4. Grieves, M.: Product Lifecycle Management. McGraw Hill (2006)

5. Ameri, F., Dutta, D.: Product Lifecycle Management: Closing the Knowledge Loops. Computer Aided Design \& Applications 2(5), 577-590 (2005)

6. Schuh, G., Rozenfeld, H., Assmus, D., Zancul, E.: By Process oriented framework to support PLM implementation. Science Direct, Computers in Industry 59, 210-218 (2008) (available online August 21, 2007)

7. Gandhi, P.: Configuration Management and PLM. International Journal of Engineering Research and Technology 2(6) (April 2013)

8. The Center for PLM Education at Oakland University, Patrick Hillberg, Ph.D

9. http://plmjim.blogspot.com/2012/03/plm-education-is-key-toinnovation-and.html ?m=1

10. http: / /www. whichplm.com/news / do-you-support-plm-ineducation.html

11. Gandhi, P.: Product Lifecycle Management Importance and Approach. International Journal of Applied Information Systems 5(6), 28-30 (2013) 